\title{
Preparation and characterization of activated carbons from corn cob
}

\author{
W. T. TSAI \\ Department of Environmental Engineering and Health \\ Chia Nan College of Pharmacy and Science, Tainan 717, Taiwan \\ C.Y. Chang and S.L. LeE \\ Graduate Institute of Environmental Engineering \\ National Taiwan University, Taipei 106, Taiwan \\ (Received 11 April 1997; accepted in revised form I July 1997)
}

Key words - A. activated carbon, B. activation

Activated carbons are carbons of highly microporous form with both high internal surface area and porosity, and commercially the most common adsorbents used for the removal of organic compounds from air and water streams. Any cheap material with a high carbon content, low inorganics can be used as a raw material for the production of activated carbon [1]. Literature survey indicates that there have been many attempts to obtain low-cost activated carbon or adsorbent from agricultural wastes such as coconut shells [2-4], almond shells [5-9], peach stones [7], grape seeds [9], apricot stones [5,9$10]$, cherry stones $[9,11]$, olive stones $[6,7,12]$, peanut hull [13], nut shells [14], rice husks [15], oil palm shells [16], and sugarcane bagasse [17].

During the 1980's, expansion of corn plantations was followed by the generation of large quantities of agricultural waste corn cob. It was reported that the annual generation of waste corn cobs has exceeded 130,000 metric tons in Taiwan [18]. There are several ways of disposing of this waste. For example, the conversion of the biomass into energy by combustion is one of the choices to treat the waste [19]. However, this method will generate serious problem of air pollution from burning. It is a possible utilization to turn this waste material into useful and valuable products. The data of ash and the carbon content in corn cob indicate that it is a suitable raw material for the production of activated carbon $[20]$.

Basically, there are two different processes for the preparation of activated carbon: physical activation and chemical activation [1]. Physical activation involves carbonization of a carbonaceous material followed by the activation of the resulting char at a temperature between 1073 and $1373 \mathrm{~K}$ in the presence of suitable oxidizing gases such as carbon dioxide or steam. In chemical activation the precursor is mixed with a chemical agent and then pyrolyzed between 673 and $873 \mathrm{~K}$ in the absence of air. Chemical activation offers several advantages in that it is carried out in a single step combining carbonization and activation, performed at lower temperatures and therefore resulting in the development of a better porous structure, although the environmental concerns of using chemical agents for activation could be developed [21]. Besides, part of the added chemicals can be easily recovered [10,22].

The objective of the present work was to investigate the feasibility of producing activated carbons from agricultural waste corn cobs. Process parameters such as impregnation ratio of chemical activating agent to corn cob, pyrolysis temperature and soaking time were varied to examine the effects on the preparation of activated carbons by chemical activation with zinc chloride $\left(\mathrm{ZnCl}_{2}\right)$. The physical characterization of the resulting activated carbons was then analyzed in terms of BET surface area, total pore volume and pore size distribution.

Fresh, air-dried, corn cobs were first cracked and crushed to free the pitch and chaff in a hammer mill, and then sieved to several different particle sizes. Fifty grams of the sieved corn cob with mesh of 12 to 16 (average particle size of $1.435 \mathrm{~mm}$ ) was mixed in a glass flask with about $200 \mathrm{~cm}^{3}$ of $\mathrm{ZnCl}_{2}$ solutions of various impregnation ratios (i.e., with the ratio of $\mathrm{ZnCl}_{2}$ weight to corn cob weight of $0.2-2.0$ ). Impregnation was carried out at about $358 \mathrm{~K}$ on a hot plate with boilerreflux condenser for 2 hours. The sample solution was then filtered in a vacuum filter flask to collect the impregnated corn cob sample. It was then dried in an oven at $393 \mathrm{~K}$ overnight. According to the results of inductively coupled plasma-atomic emission spectrometer (ICP-AES) analysis, the actual impregnation ratios are $6.4,11.0$ and $19.8 \mathrm{wt} \%$ in comparision with the initial impregnation ratios (defined above) of $0.2,0.5$ and 1.0 , respectively. Due to operational considerations, the impregnated sample was placed at the isothermal zone of a tubular stainless steel reactor $(800 \mathrm{~mm}$ in length and $50 \mathrm{~mm}$ in diameter) instead of a quartz. reactor. This reactor was placed vertically inside an electric tube furnace controlled by the proportional integral derivative (PID) programmer to maintain a stable bed temperature. Samples were heated at a rate of $10 \mathrm{~K} / \mathrm{min}$ to the specific pyrolysis temperature in the range of 673-1073K under a nitrogen flow of about $300 \mathrm{~cm}^{3} / \mathrm{min}$ STP. Thermal treatment at each of the specified temperatures was held for 0.5-4.0 hours of soaking timc. After pyrolysis, the products was cooled, weighted. washed thoroughly with $3 \mathrm{~N}$ hot hydrochloric acid solution, filtered in a vacuum flask and then washed repeatedly with hot distilled water to remove chlorides and other residues attached to the resulting activated carbon. Finally, the product of activated carbon after vacuum filtration was dried at $378 \mathrm{~K}$ overnight and then placed in a desiccator. The notation of samples, and the conditions of their preparation are cited in Table 1. An automated surface area porosimeter (Micromeritics ASAP 2000) was used to characterize the physical properties of the activated carbon produced from the corn cobs. The values of BET surface area, the total pore 
Table 1. Physical characteristics of activated carbons obtained from corn cob with chemical activation using $\mathrm{ZnCl}_{2}$.

\begin{tabular}{lccccc}
\hline $\begin{array}{l}\text { Sample } \\
\text { code }\end{array}$ & $\begin{array}{l}\text { Pyrolysis } \\
\text { temperature (K) }\end{array}$ & $\begin{array}{l}\text { Soaking } \\
\text { time (hour) }\end{array}$ & $\begin{array}{l}\text { Impregnation ratio } \\
(\% \text { wt. })\end{array}$ & $\begin{array}{l}\text { BET surface } \\
\text { area } \\
\left(\mathrm{m}^{2} / \mathrm{g}\right), \mathrm{S}_{\mathrm{BET}}\end{array}$ & $\begin{array}{l}\text { Total pore } \\
\text { volume } \\
\left(\mathrm{cm}^{3} / \mathrm{g}\right), \mathrm{V}_{1}\end{array}$ \\
\hline $\mathrm{AC}_{114}$ & 673 & 0.5 & 100 & 535 & 0.28 \\
$\mathrm{AC}_{124}$ & 673 & 1.0 & 100 & 613 & 0.31 \\
$\mathrm{AC}_{213}$ & 773 & 0.5 & 75 & 651 & 0.33 \\
$\mathrm{AC}_{223}$ & 773 & 1.0 & 75 & 725 & 0.36 \\
$\mathrm{AC}_{214}$ & 773 & 0.5 & 100 & 960 & 0.49 \\
$\mathrm{AC}_{224}$ & 773 & 1.0 & 100 & 911 & 0.45 \\
$\mathrm{AC}_{234}$ & 773 & 2.0 & 100 & 774 & 0.35 \\
$\mathrm{AC}_{244}$ & 773 & 4.0 & 100 & 783 & 0.38 \\
$\mathrm{AC}_{215}$ & 773 & 0.5 & 150 & 1114 & 0.55 \\
$\mathrm{AC}_{225}$ & 773 & 1.0 & 150 & 1139 & 0.57 \\
$\mathrm{AC}_{216}$ & 773 & 0.5 & 175 & 1410 & 0.70 \\
$\mathrm{AC}_{226}$ & 773 & 1.0 & 175 & 1338 & 0.66 \\
$\mathrm{AC}_{314}$ & 873 & 0.5 & 100 & 750 & 0.37 \\
$\mathrm{AC}_{324}$ & 873 & 1.0 & 100 & 820 & 0.40 \\
$\mathrm{AC}_{334}$ & 873 & 2.0 & 100 & 791 & 0.39 \\
$\mathrm{AC}_{344}$ & 873 & 4.0 & 100 & 744 & 0.38 \\
$\mathrm{AC}_{414}$ & 973 & 0.5 & 100 & 747 & 0.37 \\
$\mathrm{AC}_{424}$ & 973 & 1.0 & 100 & 786 & 0.37 \\
$\mathrm{AC}_{434}$ & 973 & 2.0 & 100 & 682 & 0.33 \\
$\mathrm{AC}_{444}$ & 973 & 4.0 & 100 & 703 & 0.34 \\
$\mathrm{AC}_{541}$ & 1073 & 4.0 & 20 & 400 & 0.19 \\
$\mathrm{AC}_{532}$ & 1073 & 2.0 & 50 & 424 & 0.21 \\
$\mathrm{AC}_{542}$ & 1073 & 4.0 & 50 & 446 & 0.20 \\
$\mathrm{AC}_{514}$ & 1073 & 0.5 & 100 & 706 & 0.34 \\
$\mathrm{AC}_{524}$ & 1073 & 1.0 & 100 & 757 & 0.37 \\
$\mathrm{AC}_{534}$ & 1073 & 2.0 & 100 & 721 & 0.34 \\
$\mathrm{AC}_{544}$ & 1073 & 4.0 & 100 & 688 & 0.33 \\
\hline & & & & &
\end{tabular}

volume and the pore size distribution were those obtained from the adsorption of nitrogen at $77 \mathrm{~K}$. The total pore volume and the pore size distribution are taken from the Kelvin method and BJH method, respectively.

The adsorption isotherm (Figure 1) of the resulting activated carbon indicates a typical Type I curve of the BDDT classification of physical adsorption isotherms [23]. The Type I isotherm was therefore

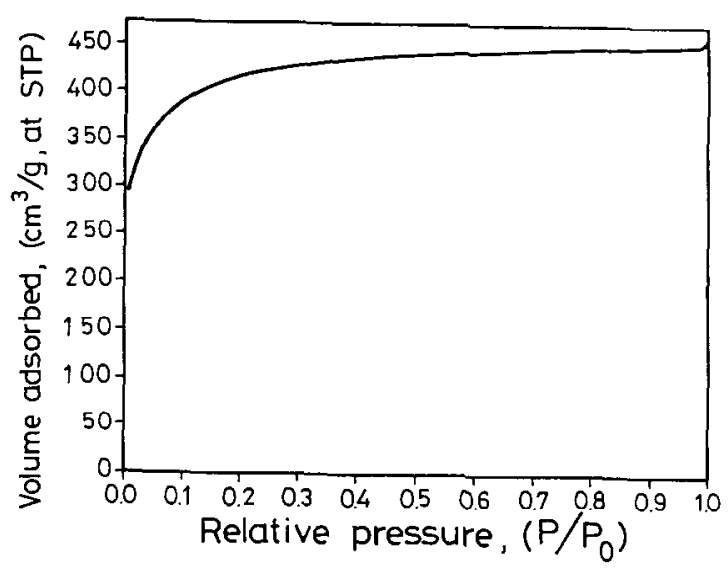

Figure 1. Adsorption isotherm of nitrogen of activated carbon $\mathrm{AC}_{216}$ at $77 \mathrm{~K}$. assumed to conform to the Langmuir equation and characterized by adsorption in a microporous solid having a small external surface area. It is noted that the interaction potential may be strong enough to bring about a nearly complete filling of the pores at a quite low relative pressure. Figure 2 shows that the pore size distribution of the resulting activated carbon reveals a sharp peak at a much lower pore diameter, about $2.0 \mathrm{~nm}$. This is a characteristics of narrow pore size distribution for materials that are essentially microporous in nature. The results of Figure 2 with most of the pores being about or less than $2.0 \mathrm{~nm}$ in diameter were consistent with the data shown in Table 1.

The data in Table 1 indicate the BET surface area and the total pore volume which then give the mean pore diameter $\left(4 \mathrm{~V} / \mathrm{S}_{\mathrm{BET}}\right)$ of the resulting activated carbon. The data for the effects of pyrolysis temperature, soaking time and impregnation ratio on the physical characteristics of the samples are also presented in Table 1. The results reveal the following points.

1. The values of the BET surface area and the total pore volume increase rapidly with increase in the impregnation ratio of $\mathrm{ZnCl}_{2}$ activating agent, i.e., $\mathrm{AC}_{213}<$ $\mathrm{AC}_{214}<\mathrm{AC}_{215}<\mathrm{AC}_{216}$ and $\mathrm{AC}_{541}<\mathrm{AC}_{542}<\mathrm{AC}_{544}$.

2. In the temperature range studied (673-1073K), the BET surface area and the total pore volume increase with pyrolysis temperature, and reach a maximum at about 


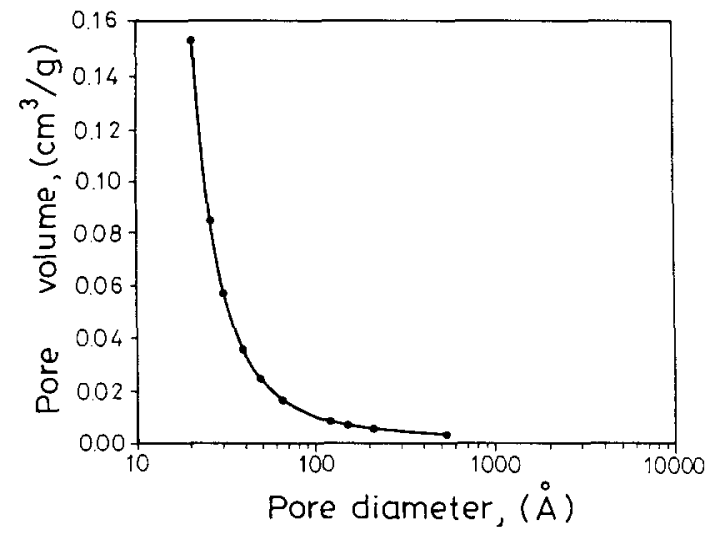

Figure 2. Pore size distribution of activated carbon $\mathrm{AC}_{216}$

$773 \mathrm{~K}$; thereafter, the trend is a decrease with pyrolysis temperature. The rate of declination is not as fast as that of increase. In our $\mathrm{ZnCl}_{2}$-activated carbon series, the increase in temperature from $773 \mathrm{~K}$ to $1073 \mathrm{~K}$ may induce a shrinkage in the carbon structure, resulting in a reduction in the surface area and the pore volume.

3. As shown in Table 1, it seems that the soaking time plays a less important role in the production of activated carbon. It is seen that, by increasing soaking time from 0.5 to 1.0 hour, the surface area and the pore volume of the samples were increased as a result of the development of porosity. However, the values thereafter are observed to decrease gradually at longer soaking time, which is possibly attributed to the gasification of the few well developed micropore wall

In conclusion, the chemical activation process was used to prepare activated carbons from agricultural waste corn cob with commonly used chemicals, $\mathrm{ZnCl}_{2}$, in the present study. The effects of major parameters during chemical activation were investigated. Under the experimental conditions investigated, the resulting activated carbons are essentially microporous materials as supported by the adsorption isotherm by the BET method. The optimal values of the parameters for the production of high surface area (about $1400 \mathrm{~m}^{2} / \mathrm{g}$ ) activated carbon are $175 \%$ impregnation ratio, $773 \mathrm{~K}$ pyrolysis temperature, and 0.5-1.0 hour soaking time for the corn cob activated with $\mathrm{ZnCl}_{2}$. Further studies on the chemical characteristics of the resulting activated carbon, and the chemical activation with potassium salts and the physical activation with $\mathrm{CO}_{2}$ from corn cob will be made.
Acknowledgements - The authors express their sincere thanks to the National Science Council, Taiwan, for its financial support of this work (Project No. NSC 84-22.11-E-041-002).

\section{REFERENCES}

1. Bansal, R.C., Donnet, J.B. and Stoeckli, F., in Active Carbon, Dekker, New York, 1988, pp.3-5.

2. Mortley, Q., Mellowes, W.A. and Thomas, S., Thermochimica Acta, 1988, 129, 173.

3. Laine, J., Calafat, A. and Labady, M., Carbon, 1989, 27, 191

4. Razvigorova, M., Goranova, M., Minkova, V. and Cerny, J., Fuel, 1994, 73, 1718.

5. Torregrosa, R. and Martin-Martinez, J.M., Fuel, 1991, 70, 1173 .

6. Domingo-Garcia, M., Fernandez-Morales, I., Lopez-Garzon, F.J, and Moreno-Castilla, C. Langmuir, 1991, 7, 339.

7. Rodriguez-Reinoso, F. and Molina-Sabio, M. Carbon, 1992, 30, 1111.

8. Guzel, F. and Tez, Z., Separation Sci. and Tech. 1993, 28, 1069.

9. Gergova, K., Petrov, N. and Eser, S., Carbon, 1994 32, 693 .

10. Philip, C.A. and Girgis, B.S., I. Chem. Terh Biotechnol., 1996, 67, 248.

11. Lussier, M.C., Shull, J.C. and Miller, D.J., Carbon, 1994, 32, 1493.

12. Gonzalez, M.I., Molina-Sabio, M. and RodriguezReinoso, F., Carbon, 1994, 32, 1407.

13. Periasamy, K. and Namasivayam, C., Separation Sci. and Tech., 1995, 30, 2223.

14. Nguyen, C., Ahmadpour, A. and Do, D.D., Adsorption Sci. Tech., 1995, 12, 247.

15. Khalil, L.B., Adsorption Sci. Tech., 1996, 13, 317.

16. Hussein, M.Z., Tarmizi, R.S.H., Zainal, Z., Ibrahim, R.and Badri, M., Carbon, 1996, 34, 1447.

17. Girgis, B.S., Khalil, L.B. and Tawfik, T.A.M., $J$. Chem. Tech. Biotechnol, 1994, 61, 87.

18. Yang, S.S., Wei, C.B., Koo, K. and Tsai, S.S., J. The Biomass Energy Society of China (Taiwan), 1991, 10, 70. (in Chinese).

19. Lin, J.L.. J. Agricultural Machinery (Taiwan), 1994, $2,27$.

20. Ebeling, J.M. and Jenkins, B.M., Trans. ASAE, $1985,28,898$.

21. Jankowska, H., Swiatkowski, A. and Choma, J., in Active Carbon, Ellis Horwood, New York, 1991, pp. $50-52$.

22. Ahamdpour, A. and Do, D.D., Carbon, 1996, 34, 471 .

23. Gregg, S.J. and Sing, K.S.W., in Adsorption, Surface Area and Porosity, 2nd ed., Academic Press, London, 1982, pp.2-4. 